\title{
NEGOSIASI PEMBENTUKAN KANTIN SEHAT DI SMK MUHAMMADIYAH 3 KOTA MAKASSAR
}

\author{
Jumriana \\ Universitas Muslim Indonesia \\ Alamat korespondensi : (Jumrianamkes@gmail.com/085242475070)
}

\begin{abstract}
ABSTRAK
Pembentukan kantin sehat disekolah sangat penting agar komunitas yang beraktivitas di sekolah tidak mengonsumsi makanan yang tidak sehat. Untuk itu dibutuhkan upaya untuk memengaruhi pihak-pihak di sekolah dalam hal ini kepala sekolah dan guru agar mendukung keberadaan kantin sehat di sekolah. Salah satu strategi efektif promosi kesehatan untuk memengaruhi keputusan dan mendorong komitmen adalah Negosiasi.Negosiasi merupakan salah satu bagian dari proses Advokasi Kesehatan dan proses untuk menyesuaikan pandangan kedua belah pihak tentang hasil yang ideal menjadi hasil yang dapat diterima semua pihak.Penelitian ini bertujuan menganalisis proses negosiasi pembentukan kantin sehat di SMK Muhammadiyah 3 kota Makassar.Penelitian ini menggunakan metode Partisipatory Action Research (PAR) yang mengkaji tindak partisipatif komunitas sekolah dan stakeholder dalam mewujudkan terbentuknya kantin sehat di SMK Muhammadiyah 3 kota Makassar. Pengumpulan data dilkukan melalui wawancara, diskusi terarah dan observasi partisipan. Data dianalisis dengan menggunakan metode analisis konten kualitatif yang dilakukan melalui tahapan pengumpulan data, pereduksian data, penyajian data dan penarikan kesimpulan yang disajikan dalam bentuk narasi, skema, dan hasil observasi.Hasil penelitian menunjukkan bahwa proses negosiasi terbentuknya kantin sehat memerlukan dukungan dan partisipasi aktif dari komunitas sekola dan stakeholder. Pembentukan kantin sehat di SMK Muhammadiyah 3 melalui tahapan identifikasi masalah, sosialisasi pembentukan komitmen, penyusunan kerangka model dan pembentukan kantin disekolah serta dibutuhkan Tim Pemantau dan tim Evaluasi dalam proses keberlanjutan program Kantin Sehat di Sekolah.
\end{abstract}

Kata kunci: Negosiasi, kantin sehat.

\section{PENDAHULUAN}

Ketersediaan dan keamanan pangan merupakan hak dasar manusia. Saat ini masalah tersebut menjadi keprihatinan dunia karena ratusan juta manusia dilaporkan menderita penyakit akibat keracunan pangan, (Hamida, 2012). Salah satu kelompok masyarakat yang sering mengalami masalah akibat keracunan makanan adalah anak sekolah. Jajanan anak sekolah berisiko terhadap cemaran biologis atau kimiawi yang banyak mengganggu kesehatan, baik jangka pendek maupun jangka panjang. Berdasarkan data kejadian luar biasa (KLB) pada jajanan anak sekolah tahun 2004-2006 (BPOM, 2009).

Berdasarkan data yang diperoleh dari BPOM provinsi Sulawesi Selatan, pada pengawasan pangan jajanan anak sekolah dasar di 16 kabupaten/kota menunjukkan $79,8 \%$ sampel memenuhi syarat (Boraks, Rhodamin B, Siklamat, Sakarin) (BPOM 2011).

Berdasarkan data hasil pengawasan, penyalah gunaan bahan berbahaya masih cukup signifikan, dimana pada tahun 2016, terdapat $7,29 \%$ sampel dari total 7.752 sampel yang diambil dan diuji pada saat pengawasan rutin masih mengandung bahan berbahaya (Formalin, Boraks, Methanil Yellow, dan Rhodamin-B). Perhatian lain Badan POM diantaranya hasil pengawasan Pangan Jajanan Anak Sekolah tahun 2016 juga menunjukkan $39 \%$ sampel dari total 627 sampel yang diambil dan diuji tidak memenuhi syarat karena cemaran mikroba (Angka Kapang \& Khamir, MPN Coliform dan Angka Lempeng Total), dan mengandung pemanis buatan yang berlebih. Keadaan tersebut menunjukkan bahwa kesadaran pelaku Usaha terkait hygiene dan sanitasi masih kurang. Selanjutnya, Berdasarkan laporan Kejadian Luar Biasa (KLB) yang terima Badan POM pada tahun 2016, Sebanyak 6.136 orang terpapar pangan yang diduga menyebabkan keracunan, 3.413 orang sakit, dan 8 orang meninggal dunia.

Banyaknya masalah keamanan pangan jajanan disebabkan penjaja pada umumnya belum memenuhi syarat sesuai Permenkes Nomor 236/Menkes/Per/IV/1997 yang telah disempurnakan dalam keputusan Menteri Kesehatan RI No. 942/Menkes/SK/VII/2003 tentang persyaratan higiene dan sanitasi makanan jajanan. Hal ini menyebabkan 
perlunya pengawasan dari pihak sekolah dalam membuat peraturan mengenai makanan jajanan sehat dan menggiatkan kembali peran Usaha Kesehatan Sekolah (UKS).

Pembentukan kantin sehat di sekolah sangat penting agar komunitas yang beraktivitas di sekolah tidak mengonsumsi makanan yang tidak sehat. Untuk itu dibutuhkan upaya untuk memengaruhi pihakpihak disekolah dalam hal ini kepala sekolah dan guru agar mendukung keberadaan kantin sehat di sekolah, salah satu strategi efektif promosi kesehatan untuk memengaruhi keputusan dan mendorong komitmen adalah negosiasi.

Negosiasi adalah cara yang terbaik dalam membantu kebijakan dari pihak-pihak terkait. Untuk mendapat partisipasi atau dukungan dibutuhkan Negosiasi kepada pihak yang terkait dalam menginisiasi terbentuknya kantin sehat yang diharapkan dapat menyediakan jajanan sehat terutama bagi siswa di sekolah.

Berdasarkan penelitian Nathan, and Nocole (2016) sebelumnya tentang Effectiveness of a multicomponent intervention to enhance implementation of a healthy canteen policy in Australian primary schools yang dilakukan di Sekolah dasar katolik dan sekolah dasar negeri di new South Wales, Australia, mendapatkan bahwa Multi komponen intervensi dibutuhkan dalam meningkatkan implementasi terhadap kebijakan kantin sehat. Dengan adanya dukungan sekolah terhadap kebijakan ini dapat meningkatkan perilaku diet pada anak.

Berdasarkaan hasil observasi di lokasi penelitian pada tanggal 10/09/2018 pada SMK Muhammadiyah 3 Makassar, masih banyak kantin yang sanitasi dasarnya tidak memenuhi syarat kesehatan. Seperti pewadahan sampah yang tidak tertutup, kotor dan tidak ada pemisahan antara sampah basah dan kering serta ditemukan sampah yang masih berserakan di kantin. Letak kantin sekolah tidak jauh dari toilet. Dan adanya sampah yang berserakan dapat mendukung terciptanya tempat perkembang biakan lalat yang dapat menularkan penyakit, hasil olahan jajanan seperti gorengan dengan minyak goreng terpakai berkali-kali membuktikan tidak sehatnya makanan yang diproduksi. Dan hasil wawancara dari beberapa Siswa dan siswi SMK. Muhammadiyah 3 Makassar, yang mengatakan bahwa makanan atau jajanan yang mereka konsumsi semua berasal dari kantin Sekolah sebab mereka tidak dibolehkan untuk keluar jajan di luar Sekolah.

\section{BAHAN DAN METODE}

Lokasi, populasi dan sampel

Penelitian ini dilakukan di SMK

Muhammadiyah 3 Makassar, Jalan Muhammadiyah No. 51 B Kota Makassar. Pemilihan sekolah ini karena kantin di sekolah SMK Muhammadiyah 3 Makassar menurut pengamatan masih sangat jauh dan belum memenuhi standarisasi kantin sehat, oleh sebab itu peneliti ingin melakukan negosiasi dengan pihak terkait di sekolah agar kantin di sekolah tersebut dapat memenuhi beberapa standarisasi kantin sehat.

Informan dalam penelitian Paticipatory Action Research (PAR) merupakan pihak yang mempunyai kepentingan atau pihak yang berpartisipasi untuk menghasilkan suatu perubahan sosial sebagai berikut:

1. Komunitas Sekolah yang terdiri dari kepala sekolah, guru, orang tua siswa dan penjaja makanan yang berada di lingkungan SMK. Muhammadiyah 3 Makassar yang akan menjadi partisipasi dalam penelitian ini, di mana komunitas sekolah yang nantinya akan mengambil bagian penting dalam pembentukan kantin sehat di sekolahnya

2. Kepala Seksi Sertifikasi Layanan Informasi Konsumen Balai POM di Kota Makassar sebagai informan yang mengetahui tentang pelaksanaan program Aksi Nasional Pangan Jajanan Anak Sekolah di Kota Makassar yangn akan mampu memberikan gambaran kondisi keamanan pangan jajanan di Kota Makassar.

3. Kepala Seksi Kesehatan Lingkungan, Kesehatan kerja dan Olahraga Dinas Kesehatan Kota Makasar yang diharapkan mampu memberikan informasi tentang kondisi kantin sekolah yang ada di Kota Makassar dan peran Dinas Kesehatan dalam pengawasan pangan jajanan anak sekolah.

4. Sekretaris Dinas Pendidikan Kota Makassar yang membawahi SMK. Muhammadiyah 3 Kota Makassar yang diharapkan dapat berpartisipasi dan berperan aktif dalam membantu mewujudkan terbentuknya kantin sehat di SMK. Muhammadiyah 3 Makassar.

Tehnik pengambilan data

1. Wawancara

Wawancara merupakan teknik pengumpulan data yang digunakan pada penelitian kualitatif.

2. Disikusi Kelompok Terarah (Focus Group Discussion)

Diskusi kelompok dilakukan dengan menggunakan topik diskusi yang disusun 
sehingga wawancara yang dilakukan dapat berjalan dengan lancar namun terstuktur. Pada Identifikasi masalah FGD dilakukan pada guru dan orang tua Siswa, untuk membicarakan Situasi dan kondisi jajanan di sekolah dan tanggapan tentang pembentukan Kantin Sehat.

3. Observasi Partisipasi

Observasi partisipan dilakukan dengan mengobservasi kegiatan partispasi yang dilakukan selama berlangsungnya kegiatan.

a. Sosialisasi: kepala Sekolah, guru, orang tua Siswa dan penjaja kantin. Sosialisasi ini berupa kerja sama dan negosiasi tentang pembentukan Kantin sehat.

b. Pembentukan komitmen: Stakeholder, guru dan penjaja Kantin. Pada pembentukan komitmen ini harus dilakukan rapat atau musyawarah untuk mendapatkan hasil yang memuaskan.

c. Menentukan strategi dan menyusun kerangka model kantin sehat serta menyepakati hasil dibutuhkan kerja sama dari komitmen yang telah disepakati serta mengamati proses penyusunan dan pembentukan kantin Sehat di Sekolah.

\section{HASIL PENELITIAN}

1. Identifikasi Masalah

a. Gambaran situasi dan Observasi kantin SMK Muhammadiyah 3 kota Makassar.

Keberadaan kantin sekolah sangat diperlukan sebagai salah satu fasilitas pelayanan bagi siswa siswi disekolah. Namun, fasilitas ini umumnya masih kurang mendapat perhatian, baik dari pihak sekolah maupun pemerintah setempat. Untuk mendapatkan gambaran situasi dan kondisi kantin SMK MUhammadiyah 3 Makassar dilakukan dengan observasi langsung dikantin sekolah.

Hasil observasi terhadap kantin SMK Muhammadiyah 3 Makassar masih terdapat sampah yang berserakan disekitar kantin dan betuk bangunan kantin masih semi permanen yang digunakan pedagang untuk berjualan.

b. Hasil Wawancara Komunitas Sekolah

Sekolah telah memiliki kantin yang masih semi permanen walaupun dengan bangunan sederhana kantin telah dilengkapi wastafel, meja dan kursi makan. Kantin ini dikelola oleh pihak sekolah, penjaja pangan dibebankan iuran perhari yang dipergunakan untuk perbaikan kantin. Kendala yang dihadapi adalah masih kurangnya bangunan kantin sehingga belum mampu menampung semua siswa.

c. Hasil diskusi kelompok dengan orang tua siswa.

Berdasarkan hasil FGD dengan informan orang tua siswa tentang swadaya orang tua dalam perbaikan kantin maka disusun skema berikut ini:

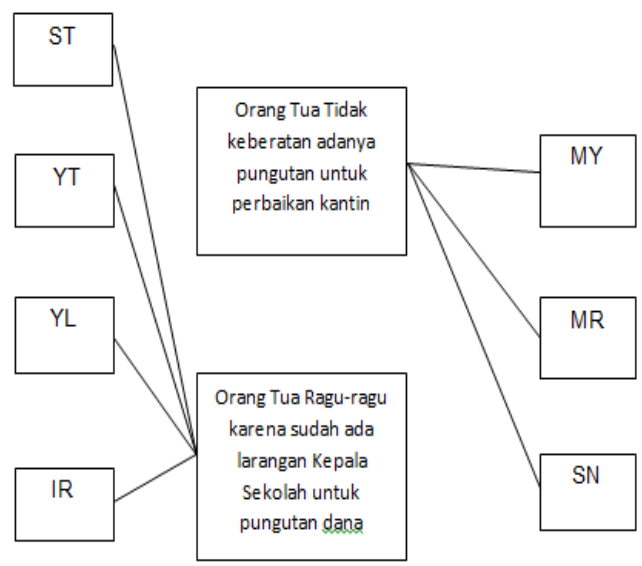

Gambar 2. Skema hasil FGD mengenai swadaya orang tua dalam perbaikan kantin di SMK Muhammadiyah 3 Makassar.

Berdasarkan skema diatas diketahui bahwa orang tua tidak keberatan dengan adanya swadaya orang tua dalam membantu perbaikan kantin di SMK Muhammadiyah 3 Makassar. Namun hal ini terkendala dengan adanya peraturan dari kepala sekolah untuk tidak memungut biaya dari orang tua siswa sehingga pembangunan kantin terkendala masalah pendanaan dan harus menunggu bantuan.

d. Peran Instansi dalam pengawasan PJAS

Tugas dan fungsi Instansi dalam Pengawasan PJAS, dalam penanganan pangan jajanan anak sekolah, Dinas Pendidikan dan Kebudayaan Kota Makassar belum memiliki program khusus yang mengawasi pangan jajanan namun Dinas Pendidikan dan Kebudayaan memberikan dukungan terhadap program terkait yang dilakukan seperti Dinas Kesehatan dan Balai POM.

e. Partisipasi dan dukungan dalam Pembentukan Kantin Sehat

Pembentukan Pemodelan Kantin Sehat di SMK. Muhammadiyah 3 kota 
Makassar tidak akan mampu berjalan dengan lancar tanpa adanya dukungan dari stakeholder terkait, Peran masingmasing dalam membatu Komunitas Sekolah untuk mempersiapkan dan membantu dalam proses penyusunan kerangka Model Kantin Sehat yang akan di terapkan.

Kerjasama dan komitmen sangat dibutuhkan dalam rangka pembentukan pemodelan Katin Sehat

f. Pentingnya Regulasi dalam pembentukan Kantin Sehat

Berdasarkan Wawancara dengan ketiga informan dari instansi terkait, regulasi yang mengatur tentang Kantin Sehat dan Pengawasan pangan jajanan anak Sekolah menjadi Kekuatan yang besar untuk meningkatkan keamanan pangan dan gizi anak sekolah. Peraturan ini juga akan mendorong adanya anggaran dalam penyediaan fasilitas kantin di sekolah.

2. Proses Sosialisasi dan Penentuan Strategi

Sosialisasi dilaksanakan pada tanggal 26 Oktober 2018 bertempat di Kantor SMK Muhammadiyah 3 Makassar, dengan peserta sosialisasi terdiri dari guru, orang tua siswa dan instansi terkait. Nasasumber pada kegiatan ini adalah kepala sekolah. Pelaksanaan Sosialisasi tentang Pembentukan Kantin Sehat yang dilaksanakan oleh Kepala Sekolah sebagai pimpinan sekolah, yang dihadiri oleh guru, orang tua Siswa dan penjaja Kantin. Sosialisasi ini dimaksudkan memberikan pengetahuan kepada pihak-pihak yang terkait mengenai pentingnya Kantin sehat dalam hal ini kepala sekolah yang memberi pemaparan tentang hal-hal yang menyangkut tentang kebersihan pangan jajanan Anak Sekolah, berhubung karena keadaan Kantin yang tidak memungkinkan untuk menampung siswa untuk jajan di Kantin. Berikut gambar pada saat sosialisasi dilaksanakan,

Sosialisasi ini diharapkan dapat merubah pemikiran atau perilaku komunitas sekolah tentang pentingnya pembentukan Kantin Sehat. Dengan sosialisasi ini diharapkan komunitas sekolah dapat bekerjasama dalam proses pembentukan Kantin yang akan dilaksanakan agar kiranya semua dapat mengawasi keadaan Kantin dan Praktik keamanan pangan. Kantin sekolah hanya pelengkap saja dan harus dikelola dengan baik. Tujuan dari sosialisasi ini untuk menyamakan persepsi dari komunitas sekolah tentang pentingnya Kantin Sehat di
Sekolah. Kegiatan ini dihadiri oleh beberapa guru, orang tua siswa dan penjaja Kantin dengan kesepakatan bersama akan ikut berpartisipasi dalam pembentukan Kantin Sehat di Sekiolah. Hasil dari Sosialisasi ini adalah Komunitas Sekolah bersedia berpartisipasi dalam pembentukan Kantin Sehat Di Smk. Muhammadiyah 3 Makassar.

3. Pembentukan komitmen partisipasi

Pembentukan kantin sehat dimulai dengan pembentukan komitmen dari komunitas sekolah. Komitmen partisipasi ini merupakan pernyataan kesediaan komunitas sekolah untuk mendukung dan bekerja sama dalam pembentukan kantin sehat di SMK MUhammadiyah 3 Makassar. Komitmen diawali dengan sosialisasi kepada komunitas sekolah tentang pentingnya pembentukan kantin sehat. Dimana pihak komunitas sekolah membuat Tim Negosiator yaitu Kepala Sekolah, beberapa guru, Serta peneliti dimana dalam pembentukan Tim ini dapat mengatur dalam partisipasi pembentukan komitmen dan disepakati bersama-sama untuk membentuk Kantin Sehat dalam bentuk pernyataan tertulis siap mendukung pembentukan kantin sehat.

4. Penyusunan kerangka model kantin sehat

Penyusunan kerangka model kantin sehat dilaksanakan bersama-sama. Kegiatan dalam bentuk pemaparan masukan-masukan dari stakeholder terkait tentang keamanan pangan kantin sekolah. Kerangka model ini didasarkan pada pedoman persyaratan hygiene dan sanitasi makanan jajanan Kemenkes No. 942/MENKES/SK/VII/2003 dan pedoman cara produksi pangan yang baik untuk industri rumah tangga (CPPB-IRT) HK.00.05.5.1639 Tahun 2003.

5. Pembentukan kantin sehat.

Kerangka pemodelan kantin sehat menjadi standar acuan dalam pembentukan kantin sehat di SMK MUhammadiyah 3 Makassar. Kerangka pemodelan memuat tentang hygiene dan sanitasi kantin, kebutuhan gizi anak, memilih pangan dan PJAS yang sesuai dan manajemen keamanan pangan sekolah. 
Matriks Analisis kondisi kantin sebelum dan sesudah pemodelan

\begin{tabular}{|c|c|c|c|}
\hline No & Tahap/Proses & Sebelum & Sesudah \\
\hline 1. & $\begin{array}{l}\text { Identifikasi } \\
\text { Masalah }\end{array}$ & $\begin{array}{l}\text { Masih banyak sampah yang } \\
\text { berserakan, dan belum adanya tempat } \\
\text { sampah, serta penataan ruangan kantin } \\
\text { yang belum rapid an bersih }\end{array}$ & $\begin{array}{l}\text { Sudah ada tempat sampah } \\
\text { dan penataan ruangan kantin } \\
\text { sudah rapi dan bersih. }\end{array}$ \\
\hline 2. & \begin{tabular}{|l} 
Proses \\
Sosialisasi
\end{tabular} & $\begin{array}{l}\text { Komunitas sekolah masih ragu dengan } \\
\text { adanya pembentukan kantin Sehat, } \\
\text { dikarenakan belum adanya } \\
\text { kesepakatan untuk bekerjasama dalam } \\
\text { pembentukan kantin Sehat di Sekolah }\end{array}$ & $\begin{array}{lr}\text { Komunitas } & \text { Sekolah } \\
\text { bekerjasama dan } & \text { sepakat } \\
\text { untuk ikut berpartisipasi } \\
\text { dalam pembentukan } & \text { Kantin } \\
\text { Sehat Di Sekolah. } & \end{array}$ \\
\hline 3. & $\begin{array}{l}\text { Pembentukan } \\
\text { Komitmen } \\
\text { Partisipasi }\end{array}$ & Belum ada kesepakatan. & $\begin{array}{l}\text { Sudah dibuat tim Negosiator } \\
\text { dalam pembentukan Kantin } \\
\text { Sehat. }\end{array}$ \\
\hline 4. & $\begin{array}{l}\text { Penyusunan } \\
\text { Kerangka } \\
\text { Model }\end{array}$ & $\begin{array}{l}\text { Belum ada standarisasi persyaratan } \\
\text { Kantin Sehat. }\end{array}$ & $\begin{array}{l}\text { Disusun atas dasar } \\
\text { persyaratan Standarisasi } \\
\text { BPOM tentang Jajanan Anak } \\
\text { Sekolah. } \\
\end{array}$ \\
\hline 5. & $\begin{array}{l}\text { Pembentukan } \\
\text { Kantin Sehat }\end{array}$ & $\begin{array}{l}\text { Kantin memiliki wastafel, dan penjaja } \\
\text { kantin sudah memakai celemek tapi } \\
\text { belum sarung tangan, pengaturan } \\
\text { ruang kantin yang belum rapi, dan } \\
\text { penyajian jajanan yang belum sesuai } \\
\text { standar kesehatan. }\end{array}$ & $\begin{array}{l}\text { Kantin sudah tertata rapi } \\
\text { dengan penjaja kantin } \\
\text { menggunakan celemek dan } \\
\text { kaos tangan setiap } \\
\text { menyajikan makanannya, dan } \\
\text { menjual jajanan sesuai } \\
\text { dengan standar kesehatan } \\
\text { serta sudah mengerti Pangan } \\
\text { Jajanan yang sehat untuk } \\
\text { anak-anak. }\end{array}$ \\
\hline
\end{tabular}

\section{PEMBAHASAN}

1. Identifikasi masalah

Situasi dan kondisi kantin di SMK Muhammadiyah 3 Makassar

Kantin sekolah merupakan salah satu fasilitas yang harus tersedia di sekolah sesuai dengan peraturan menteri pendidikan No. 19 Tahun 2005 Tentang Standar Nasional Pendidikan wajib memiliki sarana dan prasarana antara lain ruang kantin. Namun pada kenyataannya berdasarkan hasil penelitian tentang sekolah sehat yang dilakukan oleh pusat pengembangan kualitas jasmani Depdiknas Tahun 2007 pada 640 SD, sebanyak $40 \%$ belum memiliki kantin sementara dari yang telah memiliki kantin $(60 \%)$ sebanyak $84,30 \%$ kantinnya belum memenuhi syarat kesehatan (Lilis Nuraida, 2011).

2. Proses Sosialisasi

Sosialisasi merupakan suatu hal yang sangat penting bagi keberlangsungan hidup antar sesama manusia, karena dengan adanya sosialisasi akan membawa manfaat baik bagi manusia itu sendiri, maupun bagi lingkungan tempat ia tinggal, manusia bisa saling mengenal, mengerti dan memahami satu sama lainnya, sehingga memungkinkan akan terjadi sikap saling toleran, saling menjaga dan melindungi. Sosialisasi ialah hubungan interaktif yang dengannya seseorang mempelajari keperluan-keperluan social dan kultural yang menjadikan seseorang sebagai anggota masyarakat (Kimball Young, Gunawan, 2000).

Tujuan dari sosialisasi ini untuk menyamakan persepsi dari komunitas sekolah tentang pentingnya Kantin Sehat di Sekolah dimana Komunitas Sekolah berperan aktif dalam Sosialisasi agar tujuan dapat tercapai.

3. Negosiasi Pembentukan Kantin Sehat

Negosiasi merupakan salah satu bagian dari proses Advokasi Kesehatan. Negosiasi merupakan proses untuk menyesuaikan pandangan kedua belah pihak tentang hasil ideal menjadi hasil yang dapat diterima semua Pihak (Kemenkes RI, 2015).

Negosiasi sangat dibutuhkan dalam Proses perubahan Perilaku masyarakat dimana perubahan perilaku ini membutuhkan tekhnik yang dapat meyakinkan masyarakat dalam mengubah perilakunya.

Negosiasi Pembentukan Kantin Sehat Di SMK Muhammadiyah 3 Makassar melibatkan berbagai Pihak, baik komunitas Sekolah seperti Kepala Sekolah, Guru, Orang Tua Siswa dan Penjaja Kantin Sekolah, Dinas Kesehatan, Dinas Pendidikan Dan Balai POM.

Negosiasi Pembentukan Kantin Sehat ini melalui beberapa tahap diantaranya:

Pembentukan Komitmen Partisipasi

Pemodelan Kantin Sehat Di SMK Muhammadiyah 3 Makassar dengan menggunakan metode Participatory Action Research (PAR) berfokus pada pembentukan komitmen dalam mengumpulkan informasi terkait masalah atau isu yang dihadapi oleh Komunitas, keinginan untuk terlibat harus mendapatkan kejelasan tentang masalah yang sedang dihadapi, keputusan bersama untuk terlibat dalam tindakan individu dan atau kelompok. Untuk menghasilkan Solusi bermanfaat yang menguntungkan orangorang yang terlibat dan pembangun kerjasama antara peneliti dan partisipan dalam perencanaan, implementasi dan diseminasi hasil penelitian (Mclntyre, 2007).

4. Penyusunan Kerangka Model Kantin Sehat Kerangka model Kantin Sehat yang disusun merupakan Kerangka Model yang akan dijadikan acuan dalam Pembentukan Pemodelan Kantin Sehat di SMK Muhammadiyah 3 Makassar. Kerangka model ini berisi tentang panduan bagi pengelola Kantin Sekolah tentang 
Penerapan persyaratan keamanan Pangan dan mutu pangan, kebutuhan gizi anak sekolah, pemilihan PJAS yang sesuai dan manajemen keamanan pangan Sekolah.

Kerangka pemodelan Kantin sehat ini merupakan Standar yang dibuat secara tertulis dan telah didiskusikan bersama antara pihak sekolah dan stakeholder terkait. Suatu standar tertulis dibutuhkan untuk mendukung terbentuknya lingkungan dan perilaku makan Sehat.

5. Pembentukan Kantin Sehat di SMK Muhammadiyah 3 kota Makassar

Pembentukan Kantin Sehat ini dimulai dengan membenahi fasilitas kantin dimana peneliti bersama-sama dengan guru dan penjaja kantin melengkapi fasilitas yang harus tersedia di kantin sekolah seperti yang tertuang dalam kerangka pemodelan yaitu, tersedianya celemek, masker, sarung tangan dan penutup kepala bagi pengelola kantin, wastafel dan sabun pencuci tangan, tempat sampah dan poster-poster Edukasi yang dapat memberikan informasi kepada siswa, guru maupun penjaja pangan di Kantin tentang pentingnya keamanan pangan di kantin Sekolah. Program Kantin Sekolah Sehat merupakan Program yang dapat membantu sekolah menyediakan makanan yang aman dan Sehat (Mensink et al., 2012).

\section{KESIMPULAN}

1. Komunitas Sekolah bersosialisasi dalam rangka penentuan Strategi dalam mewujudkan kantin Sehat.

2. Komunitas sekolah dan stakeholder berkomitmen untuk berpartisipasi dalam pembentukan Kantin Sehat di SMK Muhammadiyah 3 kota Makassar.

3. Telah tersusun Kerangka pemodelan kantin sehat yang dapat menjadi acuan pembentukan Kantin sehat di sekolahsekolah di kota Makassar.

4. Telah tersedia kantin Sehat di SMK Muhammadiyah 3 , yang dapat dijadikan contoh uantuk kantin-kantin lainnya yang dibentuk dengan metode Participatory Action Research (PAR) dalam penelitian ini.

\section{SARAN}

1. Diperlukan kolaborasi dan kemitraan serta Peran Aktif Dinas Pendidikan, Dinas Kesehatan dan Balai POM dalam menginisiasi Sekolah-sekolah lain untuk membentuk kantin Sehat.

2. Diperlukan adanya Tim Pemantau dari pihak Stakeholder untuk memantau Kantinkantin di Sekolah agar kebersihan Kantin Tetap terjaga.

3. Diperlukan Tim Evaluasi untuk Kantin Sekolah di SMK MUhammadiyah 3 Makassar.

\section{DAFTAR PUSTAKA}

BPOM. (2009). Desain dan Petunjuk Teknis Kegiatan Aksi Nasional Pangan Jajanan Anak Sekolah (PJAS) yang Aman, bermutu dan bergizi (D. B. P. K. P. d. B. Berbahaya, Trans). Jakarta: Badan Pengawas Obat dan Makanan Republik Indonesia.

BPOM (2014). Laporan tahunan Tahun 2014: Balai Pengawas obat dan makanan di Makassar.

BPOM. (2011). Hasil Pemetaan Kasus Keracunan di Indonesia. Jakarta: Badan Pengawas Obat dan Makanan Republik Indonesia.

Cortese, R. D. M., Veiros, M. B., Feildman, C., \& Cavalli, S. B. (2016). Food safety and hygiene practices of vendors during the chain of street food production in Florianopolis, Brazil: A cross-sectional study. Food Control, 62, 178-186.

Deschesnes, M., Couturier, Y., Laberge, S., \& Campeau, L. (2010). How divergent conseptions among health and education stakeholders influence the dissemination of healthy schools in Quebec. Health promotion international, daq040.

Dwiastuti, M., Gambaran Pengetahuan, Sikap dan Perilaku Para Pedagang Makanan terhadap penyajian Makanan di Kantin Kampus masih kurang. Fakultas Kedokteran Universitas Hasanuddin. Makassar

Frahsa, A., Rutten, A., Roeger, U., Abu-omar, K., \& Schow, D. (2014). Enabling the Powerful Participatory action research with local policymakers and professionals for physical activity promotion with women in difficult life situations. Health promotion international, 29(1), 171-184.

Hevi, M., Mardiana. (2016). Kebijakan Sekolah Dalam Pemilihan Makanan Jajanan pada Anak Sekolah Dasar.(http://Journal.unnes.ac.id/sju/index.php/jhealthedu/). 
Hung, T. T. M., Chiang, V. C. L., Dawson, A., \& Lee, R. L. T. (2014). Understanding of factors that enable health promoters in implementing health-promoting Schools: a systematic review and narrative synthesis of qualitative evidence. Plos one, 9 (9), e 108284.

Young, I., St Leger, L., \& Buijs, G. (2013). School health promotion: evidence for effective action. Background paper SHE factsheet, 2.

Young et al, 2013. Publication Abstract, Errotum was published as atmos. Chem.Phys.,13,5401-5402, doi:10.5194/acp-13-5401-2013. 